S Moghimi, M Soleimani and R Soltani

Department of Ophthalmology, Farabi Eye

Research Center, Tehran University of Medical

Sciences, Tehran, Iran

E-mail: sasanimii@yahoo.com

We state that our only interest is academic and that we have no financial interest in this publication.

Eye (2009) 23, 1481-1483; doi:10.1038/eye.2009.61; published online 17 April 2009

Sir,

\section{Transient amaurosis with intracameral lidocaine}

Intracameral lidocaine is often used to augment topical anesthesia during ocular surgery. This is a safe and effective method of anesthesia that eliminates discomfort caused by tissue manipulation and thus improves patient cooperation. Although rare, complications can occur. We describe a case of a rare complication with intracameral lidocaine.

\section{Case report}

We report a patient who underwent peripheral iridectomy under topical anaesthesia, augmented by intracameral lidocaine $1 \%$. He had vitrectomy for retinal detachment years ago, and vision was $20 / 70$. He underwent a recent repeat vitrectomy with secondary anterior chamber intraocular lens inserted for dislocation of posterior chamber intraocular lens. The surgery was uneventful, but when the dressing was removed an hour later, he noted complete loss of vision. Vision was perception of light with the presence of a relative afferent pupillary defect (APD). Anterior and posterior segment was normal, with no evidence of disc swelling or cherry red spot. Carotid examination revealed no bruit. He reported gradual return of vision over $4 \mathrm{~h}$. Within $20 \mathrm{~h}$, vision improved to counting fingers at $3 \mathrm{~m}$ with resolution of APD. Two weeks later, vision recovered to 20/30 with no residual defects.

\section{Comment}

Intracameral lidocaine $(1 \%)$ can result in transient visual loss. ${ }^{1,2}$ The recovery period here was similar to the case of Lincoff $e t \mathrm{al}^{3}$, where inadvertent intraocular injection of lidocaine showed improvement in retinal function $4 \mathrm{~h}$ later and recovery in $16 \mathrm{~h}$. This is rare but can occur especially in cases of communication with the posterior segment, for example, ruptured posterior capsule and aphakia, where anaesthesia can diffuse readily into the vitreous cavity coming into direct contact with the retina and optic nerve. Visual recovery is complete with no apparent functional damage. Electrophysiological studies in animals injected with intraocular lidocaine ${ }^{4}$ show $b$-waves demonstrated a decrease in the amplitude and an increase in the implicit time. Electroretinogram responses recovered within $24 \mathrm{~h}$.

In the absence of a definite anaesthesia history, only after adequate investigation to rule out vascular or neurological complications, one can attribute amaurosis to intracameral lidocaine.

This case illustrates that intracameral lidocaine $1 \%$ is safe to use to augment topical anaesthesia, even when posterior capsule is not intact. The surgeon should be aware that transient amaurosis may occur. Patients can be reassured that it is reversible, although this may take up to several hours to days. In patients with a deficient capsule, or one-eyed patients, other alternatives such as subtenon or peribulbar anaesthesia can be considered.

\section{References}

1 Hoffman RS, Fine IH. Transient no light perception visual acuity after intracameral lidocaine injection. J Cataract Refract Surg 1997; 23(6): 957-958.

2 Gills JP, Johnson DE, Cherchio M, Raanan MG. Intraocular anesthesia. Ophthalmol Clin North Am 1998; 11: 65-71.

3 Lincoff H, Zweifach P, Brodie S, Fuchs W, Gross S, Kornmehl E et al. Intraocular injection of lidocaine. Ophthalmology 1985; 92(11): 1587-1591.

4 Liang C, Peyman GA, Sun G. Toxicity of intraocular lidocaine and bupivacaine. Am J Ophthalmol 1998; 125(2): 191-196.

\section{K Chia and S Teoh}

Department of Ophthalmology, Tan Tock Seng Hospital, Singapore

E-mail: kchiajw@yahoo.com

Authors have no proprietary interest in this research project and did not receive any research funding

Eye (2009) 23, 1483; doi:10.1038/eye.2008.201; published online 11 July 2008

Sir,

New fundus findings in a case of Kabuki syndrome

Kabuki syndrome is a multiple congenital anomalies/ mental retardation syndrome of unknown cause. Its five cardinal manifestations are characteristic facies, skeletal anomalies, dermatoglyphic anomalies, mental retardation, and short stature. ${ }^{1-4}$

We report a case of tortuous retinal vessels and prepapillary gliosis in Kabuki syndrome.

\section{Case report}

A 21-year-old man diagnosed with Kabuki syndrome by the medical geneticist was referred with peculiar optic discs and macula irregularities.

He was born by caesarean section following fetal distress. He was noted to have cleft soft palate, micrognathia (Figure 1), and umbilical hernia. He developed jaundice after birth and was treated with phototherapy. He also had a hypoglycaemic seizure in 